Results Sixteen participants (Mean age 20.3 ( \pm 1.2$)$ years; 10 female, 6 male) completed the study. During the hotel stay, mean sleep quality in the control group was 54.6 (AU) compared to 46.3 in the intervention group. Sleep quality of the control group increased from 54.6 in the hotel to 66.2 at home. No observed differences were statistically significant.

Discussion Overall, no statistically significant evidence was found to support the presence of the FNE in hotels or that use of one's own pillowcase reduces the FNE. However, there is still potential to build upon this research as this is an understudied area and applications in business and wellbeing.

Acknowledgments Thanks to Tom Hupe of Perkins+Will and Hilton London Metropole for supporting this project.

\section{P071 PSYCHOLOGICAL MORBIDITY IN CHILDREN WITH NARCOLEPSY}

${ }^{1}$ Rosalind Broe*, ${ }^{2}$ Janine Reynolds, ${ }^{2}$ Heather Elphick. ${ }^{1}$ The Medical School, University of Sheffield, Sheffield, UK; ${ }^{2}$ Sheffield Children's NHS Foundation Trust, Western Bank, Sheffield, UK

\subsection{6/bmjresp-2019-bssconf.71}

Introduction Narcolepsy occurs due to an inability to regulate the sleep-wake cycle, causing disturbed night-time sleep and excessive daytime sleepiness. Children and young people with narcolepsy have increased psychiatric illness, compared to healthy controls. A recent study of 31 paediatric narcolepsy patients found $43 \%$ had psychiatric comorbidity, compared with $10 \%$ in the general population. ${ }^{1}$

The aim of this service evaluation was to determine whether Sheffield Children's Hospital narcolepsy patients have increased psychological morbidity in order to inform service development.

Methods 43 patients, aged 4-16 years, and their parents were given Revised Children's Anxiety and Depression Scale (RCADS) questionnaires in clinic [Service Evaulation SE1473]. Software produced by the developer was used to analyse the results, using data from a cohort of children and parents separated by gender and American school grade.

Scores are divided into: Separation Anxiety, General Anxiety, Panic, Social Phobia, Obsessive Compulsive Disorder and Depression. Results 34 patients and parents completed their questionnaires. A positive score was defined by a $\mathrm{T}$ score $>65$, indicating clinically significant anxiety or depression. 16 patients scored positively based on their questionnaires and 25 scored positively based on their parent's questionnaires, giving psychological morbidity rates of $47 \%$ and $74 \%$ respectively. The category scored positively in most frequently was depression: 15 patients and 23 parents' questionnaires scored positively here. Scoring for anxiety was lower: 13 in the parent and 2 in the patient questionnaires.

Discussion This service evaluation showed raised levels of anxiety and depression in Sheffield Children's Hospital narcolepsy children and young people, compared with national averages. Regular psychological assessment and early intervention for patients would be appropriate, given the results shown here and these results will be put forward as part of a future business case.

\section{REFERENCE}

1. Szakacs, et al. Psychiatric comorbidity and cognitive profile in children with narcolepsy with or without association to the H1N1 influenza vaccination. Sleep 2015.

\section{P072 USING THE 'SLEEP WISE' PROGRAMME TO IMPROVE SLEEP FOR PATIENTS ACCESSING A COMMUNITY PAEDIATRIC SERVICE}

Janice Jenner* , Jane Armstrong. Hunrosa, LISKEARD, UK

\subsection{6/bmiresp-2019-bssconf.72}

Introduction It may be assumed that children who are patients of a community paediatric service are more difficult to support in order to improve their sleep. This assumption could be due to their condition or the possibility of a co-morbid sleep disorder. It may also be due to parent's reluctance to talk about sleep as there are other issues seen to be more important or even they think that sleep can't be improved. The Sleep Wise programme, commissioned by a CCG, sought to improve sleep for this cohort.

Method 50 children 3 to 12 years old were assessed over 12 months (2018 to 2019) and received a sleep programme, which addressed lifestyle and behavioural changes, working with the family's priorities. Before and after scores were taken for sleep disturbance and the parents rated the impact on family life before and after. A questionnaire was administered once involvement ended.

Results We found that there was a high degree of adherence to the sleep assessment: $88 \%$ followed the programme through. 99\% reported improved sleep. Average sleep disturbance reduced from 5.5 to 1.9 out of a possible 8. A whole range of factors (self rated) improved. Rating recorded before and after:

Child's daytime behaviour

$\begin{array}{lc}\begin{array}{l}6.86 \\ \text { My ability to work to my full potential } \\ 5.86\end{array} & 3.13 \\ \text { Effect on quality of life and health } & 3.58 \\ 6.89 & \\ \text { Effect on siblings } & 3.17 \\ 6.11 & \\ \text { Child's happiness and health } \\ 4.97\end{array}$

$80 \%$ of those already taking melatonin to help them to sleep came off melatonin completely. $77 \%$ avoided medication after Sleep Wise.

Discussion The 'Sleep Wise' method of engaging children and families was highly effective in empowering families in some of the most challenging circumstances to take control of their child's sleep and achieve success.

\section{P073 THE EFFECT OF SLEEP INTERRUPTION AROUND RAMADAN ON COGNITIVE FUNCTIONING IN 18-25 YEAR-OLD UNIVERSITY STUDENTS}

${ }^{1}$ Isha Parekh*, 'Daanyaal Khan, 'Moussa Al-Rufayie, ${ }^{2}$ William Jackson, ${ }^{1,3}$ Mary Morrell. ${ }^{1}$ Clinical Research and Innovation Theme, Imperial College School of Medicine, London, UK; ${ }^{2}$ Clinical Research and Innovation Theme, Student Mentor Imperial College School of Medicine, London, UK; ${ }^{3}$ Academic Unit of Sleep and Ventilation, National Heart and Lung Institute, London, UK

\subsection{6/bmjresp-2019-bssconf.73}

Introduction Ramadan involves sleep interruption (specifically during REM sleep), ${ }^{1}{ }^{2}$ which could affect cognition and consequently have a negative effect on students during revision time and examinations. This study aimed to investigate the 